\title{
Géneros de lectura preferidos por los alumnos extremeños Datos y análisis
}

\author{
Ramón Pérez Parejoํ, Álvaro Gutiérrez Cabezas, ${ }^{1}$ José Soto Vázquez, \\ Francisco Javier Jaraíz Cabanillas ${ }^{1}$ y José Antonio Gutiérrez Gallego ${ }^{2}$

\begin{abstract}
${ }^{1}$ Universidad de Extremadura. Departamento de Didáctica de las Ciencias Sociales, de las Lenguas y de las Literaturas, Facultad de Formación del Profesorado. Cáceres, España | rpp@unex.es / http://orcid.org/oooo-0002-7802-979X | agutierre@alumnos.unex.es / http://orcid.org/oooo-0001-7474-6049 I jsoto@unex.es / http://orcid.org/o0oo-0002-9967-5694 I jfjaraiz@gmail.com / http://orcid.org/oooo-0003-3575-3136 2Universidad de Extremadura. Facultad de Politécnica. Departamento de Expresión Gráfica. Cáceres, España I jagutier2o@gmail.com / http://orcid.org/oooo-0002-2375-7087
\end{abstract}

\begin{abstract}
Resumen
Los abundantes trabajos de investigación acerca de los hábitos de lectura en España muestran una desagregación de municipios y ciudades con escasa muestra geográfica de sus resultados. Tomando como punto de partida los estudios previos de 2007 realizados por la Fundación Germán Sánchez Ruipérez para Extremadura, nuestro trabajo pretende actualizar y ampliar los datos de hábitos de lectura aplicándolos a la realidad geográfica contemporánea y el grado de ruralidad de la región. Así, en el contexto de una encuesta propia sobre hábitos lectores en Extremadura realizada a 9.212 estudiantes de todos los niveles educativos (Primaria, Secundaria, Universidad) durante el año 2017, este estudio expone y analiza específicamente los datos obtenidos sobre los géneros preferidos atendiendo al nivel educativo y sexo de los encuestados. El estudio se completa con los datos referidos al CDU de las bibliotecas públicas y escolares de Extremadura. Como resultados más relevantes, los géneros literarios de misterio y aventuras son, en general, los más demandados en todos los niveles educativos. En la Universidad de Mayores se prefieren los de historia. La novela romántica gusta más a las mujeres que a los hombres. El género lírico no atraviesa un buen momento en cuanto a las preferencias de lectura en ninguno de los niveles educativos analizados.
\end{abstract}

\footnotetext{
Abstract

Preferred reading genres by students from Extremadura. Data and analysis. The abundant research work on reading habits in Spain shows a disaggregation of municipalities and cities with little geographical sample of their results. In this way, taking as a starting point the previous studies of 2007 for Extremadura carried out by the Germán Sánchez Ruipérez Foundation, our work intends to update and extend the data of reading habits by applying them to the contemporary geographical reality
}

\section{Palabras clave}

Hábitos de lectura Géneros literarios Extremadura Preferencias lectoras Encuesta

Keywords

Reading habits Literary genres Extremadura

Reader preferences Survey 
and the degree of rurality of the region. Thus, in the context of a survey focused on reading habits in Extremadura responded by 9.212 students of all educational levels (Primary, Secondary, University) during the year 2017, this study exposes and specifically analyzes the data obtained on the preferred genres according to the educational level and sex of participants. The study is completed with the data to the CDU of the public and school libraries of Extremadura. As a relevant result, the literary genres of mystery and adventure are, in general, the most demanded at all levels of education. In the Senior College, history is preferred. More women than men prefer romantic novels. The lyric genre is not very popular in terms of reading preferences among any of the educational levels analyzed.

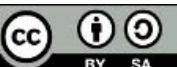

Artículo recibido: 20-03-2018. Aceptado: 20-07-2018

1. Este estudio se incluye en las actividades realizadas en el "Proyecto de investigación de los Hábitos de lectura en Extremadura", Referencia 037/17 de la Universidad de Extremadura, financiado por la Presidencia de la Junta de Extremadura. La publicación de este trabajo de investigación ha sido posible gracias a la financiación concedida por el Fondo Europeo de Desarrollo Regional (Feder) y por la Junta de Extremadura al Grupo de Investigación de Literatura Infantil y Juvenil (SEJ036, GR15006). Ayudas cofinanciadas por fondos Feder. Programa operativo Feder de Extremadura 2014-2020.

\section{Introducción ${ }^{1}$}

Las autoridades educativas y los servicios bibliotecarios institucionales hacen grandes esfuerzos económicos en la adquisición de libros o en el diseño de programas de promoción de la lectura para atraer a los usuarios a las bibliotecas. Aunque todas estas disponen de sus registros particulares, las adquisiciones no dependen directamente de ellas y, por otro lado, se echa en falta en ocasiones una visión de conjunto más amplia en cuanto a preferencias lectoras desagregadas por grupos homogéneos para implementar políticas activas ajustadas a la realidad que ayuden a mejorar los índices de competencia lectora en un área determinada. El objetivo principal del presente trabajo se centra en revelar las preferencias lectoras de los estudiantes extremeños (Primaria, Secundaria, Universidad y Programa de Universidad de Mayores). Además, se pretende dotar de una significación estadística adecuada que se sustenta en más de 9.000 encuestas durante 2017 en toda la geografía extremeña teniendo en cuenta el grado de ruralidad de esta comunidad autónoma.

La encuesta general cubría más ítems acerca de los hábitos de lectura de los estudiantes extremeños (adquisición de libros, lectura en otras lenguas, frecuencia de uso de bibliotecas, soporte de lectura, etc.). En este estudio concreto presentamos y analizamos solo las cuestiones relativas a las preferencias de lectura distinguiendo, por un lado, los niveles educativos y, por otro, el sexo de los lectores.

\section{Marco teórico y revisión de la bibliografía}

El inicio de los estudios sobre comportamientos culturales lectores se produce en la España contemporánea con las Encuestas de los hábitos de lectura que avanzó el INE en 1978. Esta investigación venía a completar el trabajo de la Fundación Bertelsmann en varios países europeos, entre otros España, en los años 1969-1994.

Uno de los trabajos pioneros en la investigación sociológica de hábitos lectores regionales lo encontramos en el estudio sobre la Educación Secundaria del País Vasco (Olaziregi Alustiza, 2000: 79-93), centrado fundamentalmente en la recepción en lengua euskera y española de obras de ficción literaria. En él se confirmaban los estudios anteriores (Poulain, 1988). Estudios posteriores (Colomer, 1993; Moret, 1999) vienen a constatar que el incremento lector en España hacia edades más tempranas, en torno a los 11 años de edad. 
Otra investigación que completaba la panorámica regional era el desarrollado por la FGSR (Fundación Germán Sánchez Ruipérez, 2007) sobre los hábitos de lectura y compra de libros de los adolescentes extremeños entre 14 y 24 años. El informe tenía su origen en las prospecciones realizadas por la Fundación en colaboración con la Consejería de Cultura de Extremadura desde 2003. Se realizaron 600 encuestas. Igualmente interesantes resultan las conclusiones sobre hábitos de lectura en Andalucía (Gil Flores, 2009), con datos de 4000 familias a través de las pruebas de diagnóstico. De 2009 es el informe Hábitos de lectura y compra de libros en Castilla-La Mancha (Fundación Germán Sánchez Ruipérez, 2009). En este se realizaron unas 2.400 entrevistas a lectores de más de 10 años, con una división territorial de poblaciones según su número de habitantes.

Dos años después, otra investigación (Muñoz Rodríguez y Hernández Martín, 2011) ayudaba a esclarecer la situación con un artículo sobre los hábitos lectores en la ESO en la provincia de Salamanca. El estudio, a través de 725 encuestas aleatorias entre jóvenes de 14 a 16 años, venía a constatar que la lectura, aunque es valorada positivamente por los encuestados, no figura entre sus preferencias durante el tiempo de ocio. Mostraba un mayor índice lector en las mujeres que en los hombres.

De reciente aparición es un trabajo sobre bibliotecas escolares y su potencial como promotoras de los hábitos lectores en alumnos y familias (Serna, Rodríguez y Etxaniz, 2017). Con un volumen de 1.528 encuestas entre niños de 8 a 12 años, concluye con la necesidad de fomentar la biblioteca escolar para mejorar los hábitos lectores, ya que su presencia per se no asegura ni incide directamente en este hábito si no viene acompañada de campañas de dinamización e integración.

En este contexto se hallan también trabajos promovidos por los gobiernos autonómicos en Cataluña (Hábitos de lectura y compra de libros en Cataluña, 2016) y en la Comunidad de Madrid iniciado en 2004 (2010).

Podemos concluir que el conjunto de trabajos estadísticos actuales sobre este campo ha sido voluminoso y diverso, bien por estudios regionales sobre la Educación Secundaria (Olaziregi Alustiza, 2000; Muñoz y Hernández, 2011), la lectura en red (Ministerio de Educación, Cultura y Deporte, 2013-2014), la importancia de la participación familiar (Gil, 2009; Ministerio de Educación, Cultura y Deporte, 2014) o sobre el sector editorial (Ministerio de Educación, Cultura y Deporte, 2016; Gremio de libreros de Madrid, 2016), que se completan con La lectura en España (Millán, 2017), entre otros.

\subsection{Nuestro estudio}

Pasados diez años del anterior estudio de este tipo en la región (FGSR, 2007), consideramos que es un buen momento para retomar esta senda de trabajos de acuerdo con las peculiaridades demográficas de la Extremadura de 2017/2018 y su grado de ruralización, lo que afecta decisivamente a los hábitos lectores. La información que actualmente puede apreciarse en los distintos informes que se editan por el Observatorio de Lectura y el Libro del Ministerio de Educación, Cultura y Deporte, así como las informaciones que se recogen por el Instituto Nacional de Estadística, aportan unos apuntes muy generales que necesitan de una mayor desagregación que atienda a las peculiaridades de esta región, su grado de ruralidad y las peculiaridades de su demografía, lo que afecta decisivamente a los hábitos lectores (Observatorio, 2015, 2016 y 2017). 


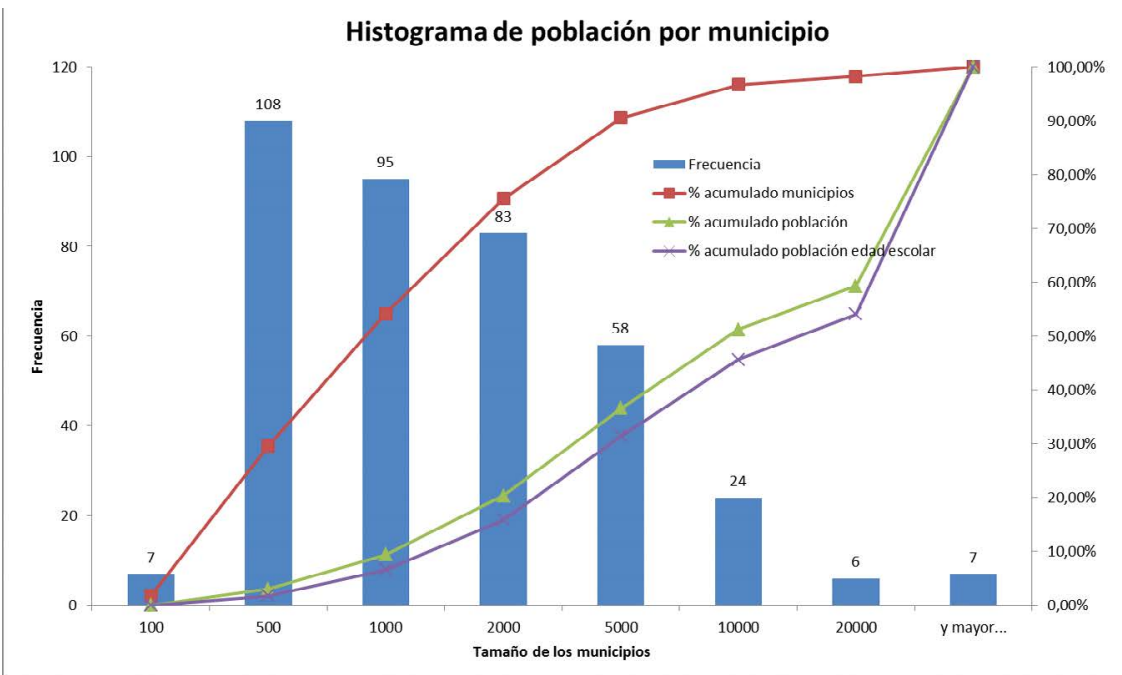

Asimismo, entendimos que convenía ampliar el espectro de edad acotado en 2008 (14 a 24 años), a todos los grupos de edad de los estudiantes (también universidad y programa de universidad de mayores). No en vano, el Informe Pisa (Ministerio de Educación, Cultura y Deporte, 2016) muestra unos niveles de comprensión lectora mejorables en relación a los entornos educativos de regiones que requieren de intervención, y Extremadura es la única región española que mantendrá las ayudas de los fondos de cohesión europeos (López-Rodríguez y Faíña, 2014; Ramajo Hernández et al., 2014; Nieto Masot y Cárdenas Alonso, 2015) entre cuyos objetivos se encuentra la inversión en educación e investigación (Mate-SánchezVal and Harris, 2014; Bleotu y Doina, 2014; Grecu, Titan y Druica., 2015; Goksu y Gungor, 2015; Iatagan, 2015).

Como han manifestado Nieto Masot y Gurría Gascón (2005), las poblaciones rurales van perdiendo población y servicios desde hace años y, al igual que se han estudiado variantes socioeconómicas para entender este problema mediante el diseño de atlas socieoeconómicos (Junta de Extremadura, 2017), es necesaria la investigación de aspectos culturales y educativos que se ocupen de municipios rurales o con escasa entidad poblacional, ya que las poblaciones por debajo de los 10000 habitantes suponen en Extremadura más del 96\% de los municipios (Gráficos 1 y 2), lo que supone una gran dispersión de la población.

El tipo de muestreo territorial utilizado para la correcta estratificación espacial de las variables ha sido el bietápico estratificado, dividiendo el territorio en dos partes: de un lado las siete poblaciones con más de 20.000 habitantes y por otro la agrupación de municipios en doce grandes zonas (Mapas 1 y 2). En estas doce zonas áreas rurales se han clasificado los municipios en función de su entidad poblacional ( $<1.000$ habitantes, de 1.000 a 2.000 , de 2.000 a 5.000, de 5.000 a 10.000 y de 10.000 a 20.000) y se han seleccionado una o varias dentro de cada intervalo en los que se ha realizado la encuesta a los estudiantes de Educación Primaria (Tabla 1). 
Número de municipios extremeños en función de su Porcentaje de población en función del tamaño de los tamaño (2016)

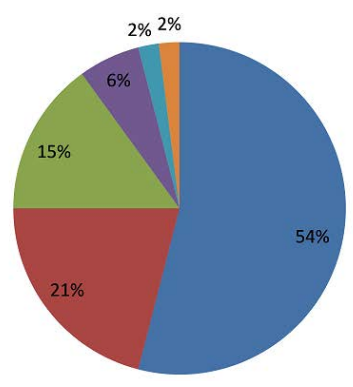

匹 $<1.000$ hab.

1.000-2.000 hab

$=2.000-5.000 \mathrm{hab}$

5.000-10.000 hab.

10.000-20.000 hab

프. $>20.000$ hab. municipios extremeños (2016)

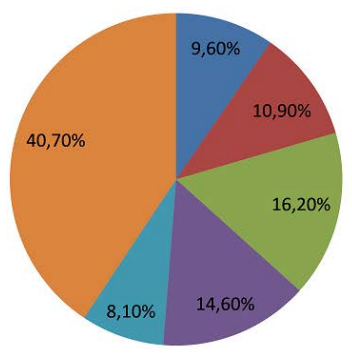

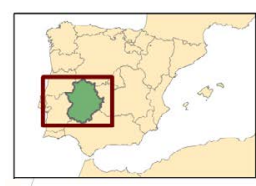

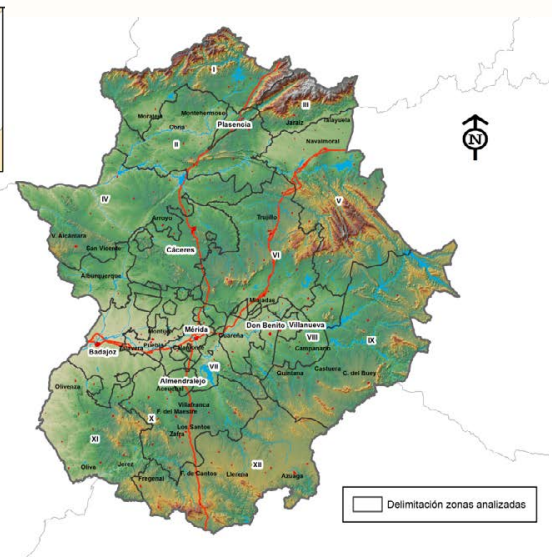

Mapa 1. Área de estudio

Zonas rurales

Ley 45/2007 de Desarrollo Rural Sostenible

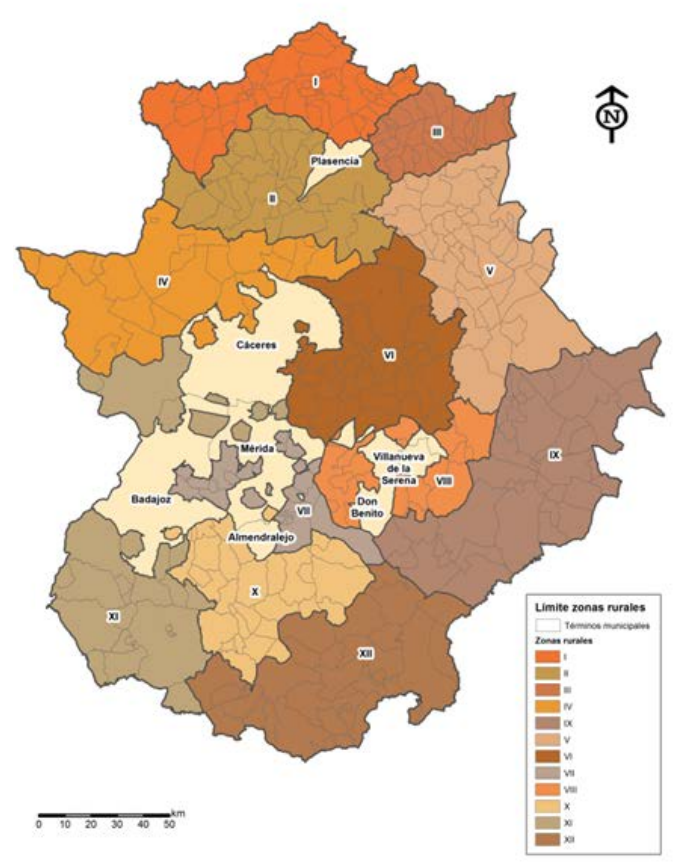

Gráfico 2. Comparativa entre número municipios/entidad poblacional y tamaño en 2016

Mapa 1. Area de estudio 


\begin{tabular}{|c|l|}
\hline Zonas Rurales & Comarcas naturales y/o funcionales que comprenden \\
\hline I & $\begin{array}{l}\text { Las Hurdes, Sierra de Gata, Trasierra-Tierras de Granadilla y Valle de } \\
\text { Ambroz }\end{array}$ \\
\hline II & Valle del Alagón, Rivera de Fresnedosa y Riberos del Tajo \\
\hline III & La Vera y Valle del Jerte \\
\hline IV & Tajo Salor y Sierra de San Pedro \\
\hline V & Las Villuercas-Ibores-Jara y Campo Arañuelo \\
\hline VI & Comarca de Trujillo, Sierra de Montánchez y Zona Centro \\
\hline VII & Lácara Sur y Municipios Centro \\
\hline VIII & La Serena - Vegas Altas y Guadiana \\
\hline IX & La Serena y Siberia \\
\hline X & Río Bodión, Tierra de Barros-Matachel y Tierra de Barros \\
\hline XI & Lácara-Los Baldíos, Comarca de Olivenza y Sierra Suroeste \\
\hline XII & Aguas y Servicios de la Comarca de Llerena y Turística de Tentudía \\
\hline
\end{tabular}

\section{Método}

\subsection{Fuentes}

Para el correcto desarrollo del estudio ha sido necesario recurrir a un nutrido número de fuentes de información que van desde censos hasta encuestas de preferencias declaradas. Los censos han resultado muy útiles para definir la dimensión de la población objeto de estudio, así como para proceder a la adecuada estratificación del proceso de recogida de encuestas.

La Sección de Estadística del Servicio de Evaluación y Calidad Educativa de la Secretaría General de Educación, perteneciente a la Consejería de Educación y Empleo de la Junta de Extremadura, ha facilitado la interpretación de la distribución espacial de los alumnos de Educación no universitaria en la región de Extremadura, revelándose como una fuente imprescindible para la correcta estratificación de las encuestas, al disponer de cierta información que no recogen los censos oficiales publicados por el Instituto Nacional de Estadística (INE). Así pues, esta es la principal fuente de datos empleada en la determinación de la estratificación y del tamaño de la muestra.

Por otra parte, la Unidad Técnica de Evaluación y Calidad de la Universidad de Extremadura dispone de información muy completa de la distribución de los estudiantes universitarios en los diferentes centros. Por tanto, gracias a esta información ha sido posible adaptar la muestra seleccionada para las encuestas a la población de alumnos universitarios.

\subsection{Caracterización general de la encuesta}

El objetivo perseguido en la caracterización de los encuestados ha sido 1) estimar los gustos literarios de los estudiantes en función del sexo; y 2) establecer su diferenciación por nivel educativo y sexo.

La unidad estadística observada en todas las designaciones de las variables ha sido el individuo estudiante de Primaria, Secundaria y Universidad con 6 y más años. 
Para alcanzar los objetivos propuestos, se ha considerado sobre el perfil biográfico la designación de las variables: sexo, edad.

La encuesta de opinión se ha realizado a los estudiantes que se encontraban en el momento de la entrevista en los centros educativos (colegios, tanto públicos como concertados) de los municipios de las diferentes zonas rurales en las que se ha dividido el área de estudio, así como, a los estudiantes universitarios pertenecientes a cada una de las facultades y escuelas de la Universidad de Extremadura.

Los datos eran recogidos de un modo directo de las unidades muestrales en los centros educativos, a través de un soporte físico (papel). No obstante, el modo de recogida también podía ser indirecto, por medio de un formulario de Google Drive, donde en todo momento los alumnos eran correctamente guiados por sus profesores/encuestadores. En cualquier caso, este último modo de recogida apenas tuvo incidencia en los alumnos de Primaria, como técnica de recogida de la información (162 encuestas). Sin embargo, en Secundaria y en la Universidad fue el medio más usado para realizar las encuestas. Se realizaron 4.288 encuestas válidas a una población de 64.419 estudiantes de Primaria, 4.508 encuestas válidas a una población de 75.670 estudiantes de Secundaria y 801 encuestas válidas a una población de 19.780 estudiantes universitarios. Además de 200 encuestas de la universidad de mayores.

Atendiendo al tamaño de la muestra, se puede afirmar que el error máximo estimado es inferior al $3 \%$ para un nivel de confianza del $95 \%$. Al mismo tiempo, es necesario destacar que a la hora de mostrar los datos no se ha tenido en cuenta ningún resultado que obtuviera un valor inferior a 25 respuestas.

La encuesta se desarrolló entre febrero y junio de 2017. Los días elegidos fueron en función de la localización geográfica de los municipios que componían el ámbito geográfico de la operación. En aras de una mejor representatividad de la información obtenida, se tuvo en cuenta la población existente en la región en función del tamaño de los municipios, como se muestra en la tabla 2 que representa la distribución de las encuestas de Primaria:

\begin{tabular}{|l|c|c|c|c|}
\hline \multirow{2}{*}{ Municipios } & \multicolumn{2}{|c|}{ Educación Primaria } & \multicolumn{2}{c|}{$\begin{array}{c}\text { Total de encuestas } \\
\text { realizadas }\end{array}$} \\
\cline { 2 - 5 } & Hombre & Mujer & Mujer & Hombre \\
\hline Menos de 1.00o hab. & 1.682 & 1.477 & 357 & 324 \\
\hline 1.000-2.000 hab. & 2.788 & 2.747 & 432 & 409 \\
\hline 2.000-5.000 hab. & 4.925 & 4.436 & 761 & 724 \\
\hline 5.000-10.000 hab. & 4.936 & 4.619 & 1.097 & 956 \\
\hline 10.000-20.000 hab. & 2.966 & 2.890 & 607 & 512 \\
\hline Más de 20.000 hab. & 16.182 & 15.159 & 1.060 & 1.001 \\
\hline Total & 33.479 & 31.328 & 2.101 & 2.116 \\
\hline
\end{tabular}

Tabla 2. Alumnados matriculados agrupados por tamaño del municipio en función de la localidad del centro, curso 2016-2017
En la tabla 3 se muestra la distribución de las encuestas en función de la edad de los encuestados y el género, donde se puede apreciar una adecuada distribución de las mismas. 


\begin{tabular}{|l|c|c|c|c|c|c|c|c|c|c|c|c|c|c|c|}
\hline \multicolumn{11}{|c|}{ Encuestados por edad y sexo } \\
\hline Sexo & Total & 6 & 7 & 8 & 9 & 10 & 11 & 12 & 13 & 14 & 15 & 16 & 17 & 18 & $>18$ \\
\hline Mujeres & 4.543 & 55 & 212 & 394 & 366 & 360 & 527 & 549 & 463 & 323 & 427 & 333 & 273 & 96 & 165 \\
\hline Hombres & 4.120 & 50 & 214 & 383 & 352 & 384 & 509 & 505 & 390 & 353 & 362 & 262 & 199 & 72 & 85 \\
\hline
\end{tabular}

Tabla 3. Caracterización de la población no universitaria según sexo y edad

El cuestionario fue configurado a partir de las necesidades de información definidas por el grupo de investigación, siendo el tiempo medio previsto para la encuesta de aproximadamente 10 minutos. El cuestionario presencial fue testado en diciembre de 2016, a través de encuestados elegidos aleatoriamente en cuatro centros educativos de la ciudad de Navalmoral de la Mata (Cáceres), con el objetivo de testar la adecuación del cuestionario al nivel de la identificación de eventuales dificultades en la comprensión de las preguntas.

La realización de las encuestas dependió de la cantidad de alumnos presentes en el aula durante el período/horario de trabajo de los encuestadores. Así pues, se pretendía que siempre hubiera más de 25 alumnos que respondieran a la misma por curso o al menos centro. De igual modo, se estimaba oportuno que los cursos también fueran diversos. Por lo que, por ejemplo, si en un centro de Primaria en segundo solo estaban presentes en el aula 18 alumnos, para superar los 25 propuestos, se encuestaba preferentemente a quinto o sexto con el objeto de superar la cifra considerada como significativa estadísticamente hablando. Para la realización de las encuestas presenciales, el encuestador se dirigía a varias aulas por centro siempre acompañado por algún miembro del equipo directivo.

Después de realizar todas las encuestas en papel, se transcribían los resultados a la base de datos de forma manual. Por otro lado, a través de las hojas de cálculo generadas automáticamente por el Formulario de Google Drive, los datos eran importados a la misma base de datos en la que se tenían las transcritas. La información era analizada inicialmente a través del cálculo de diversas medidas de dispersión y centralidad propias de estadística descriptiva.

Una vez definidas convenientemente las tablas de la base de datos, se procedió a crear las consultas a través del lenguaje de interrogación SQL (lenguaje específico que da acceso a un sistema de gestión de bases de datos relacionales que permite realizar diversos tipos de operaciones), implementando la base de datos en el gestor Microsoft Access.

\section{Resultados y análisis}

\subsection{Primaria}

Conviene señalar que la suma de porcentajes del Gráfico 3 superan el cien por ciento debido a que los alumnos pudieron seleccionar más de un género literario. Dicho esto, los temas favoritos de lectura de los alumnos de Primaria son las aventuras y el misterio (Gráfico 3). Un $62 \%$ afirma preferir los libros de aventuras y un $40 \%$ las lecturas de misterio. Por otra parte, los libros de poesía y románticos apenas interesan a uno de cada diez alumnos. 


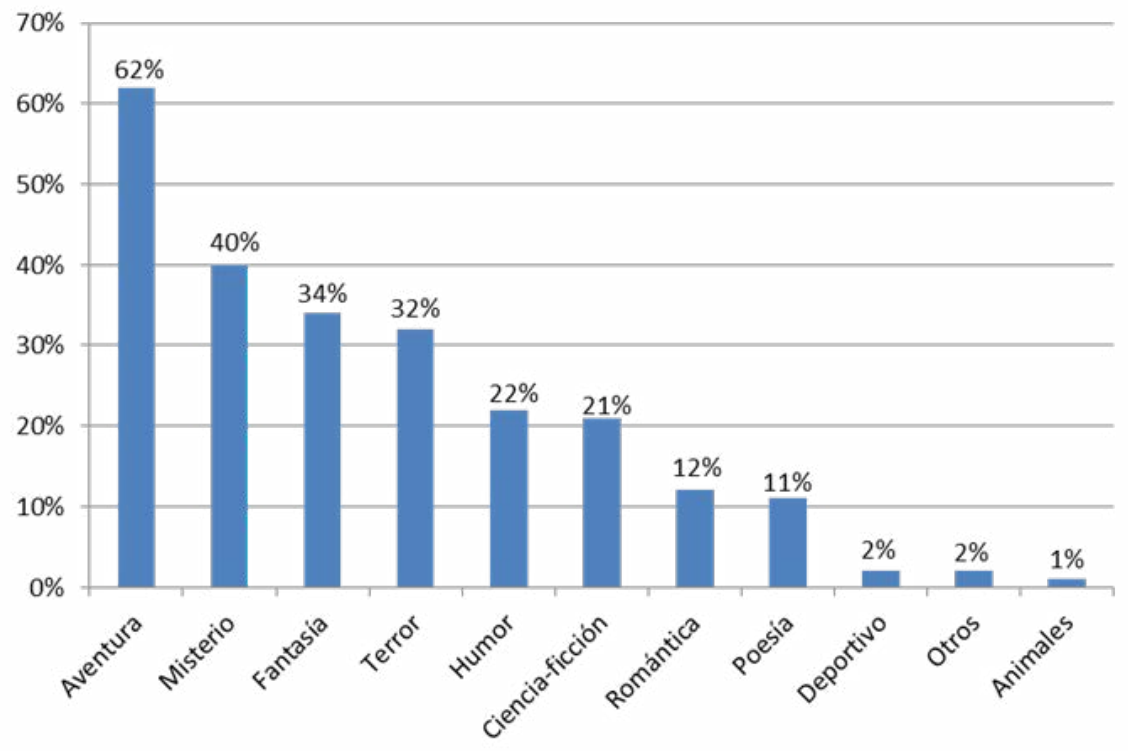

Gráfico 3. Géneros literarios favoritos en los alumnos de Primaria

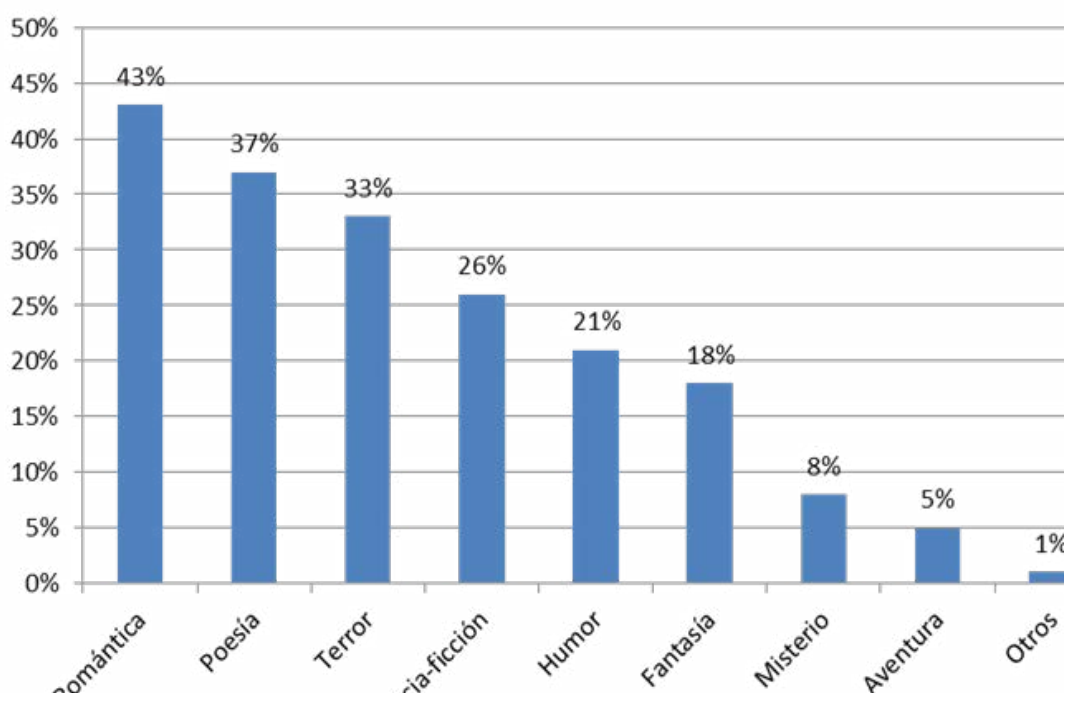

Gráfico 4. Géneros literarios que menos gustan en los alumnos de Primaria

Mujeres

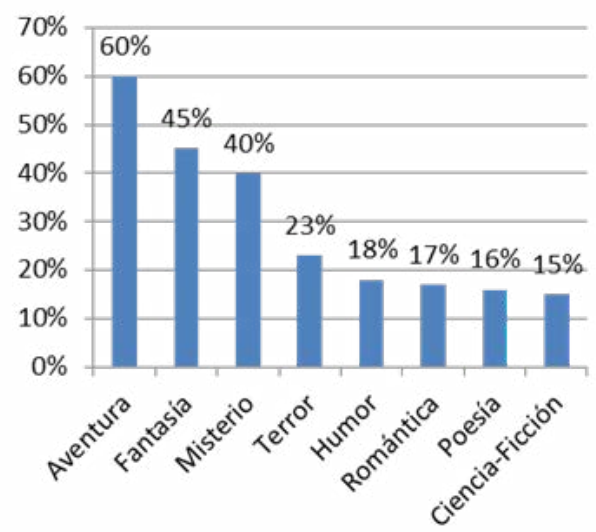

Hombres

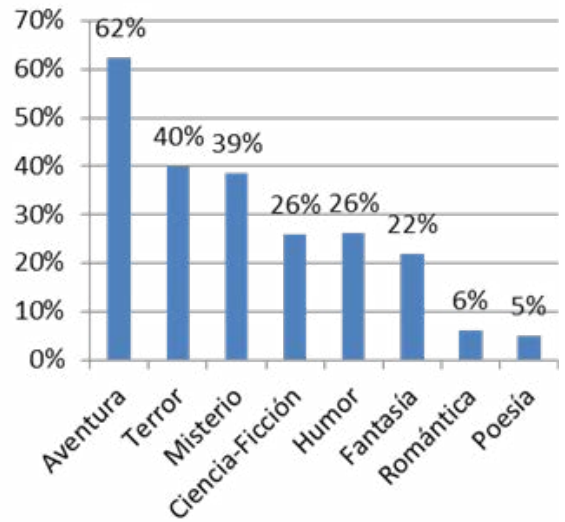

Gráfico 5. Géneros literarios favoritos en los alumnos de Primaria según el sexo 
Gráfico 6. Géneros literarios que menos gustan en los alumnos de Primaria según el sexo

Gráfico 7. Géneros literarios favoritos en los alumnos de Secundaria
Mujeres

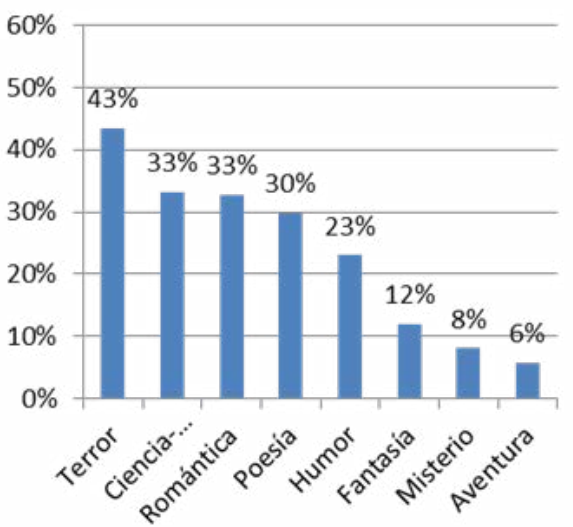

Hombres

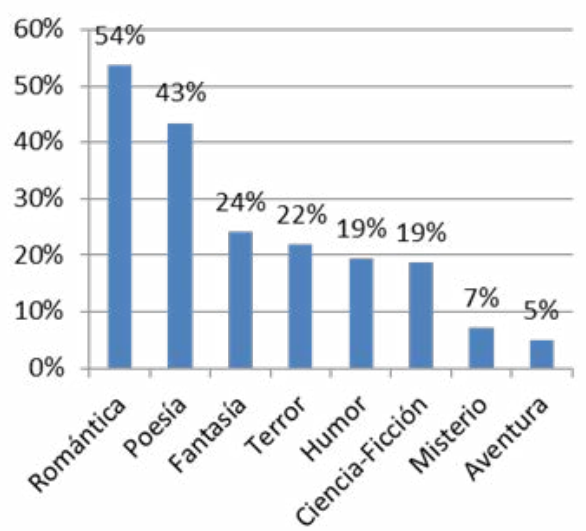

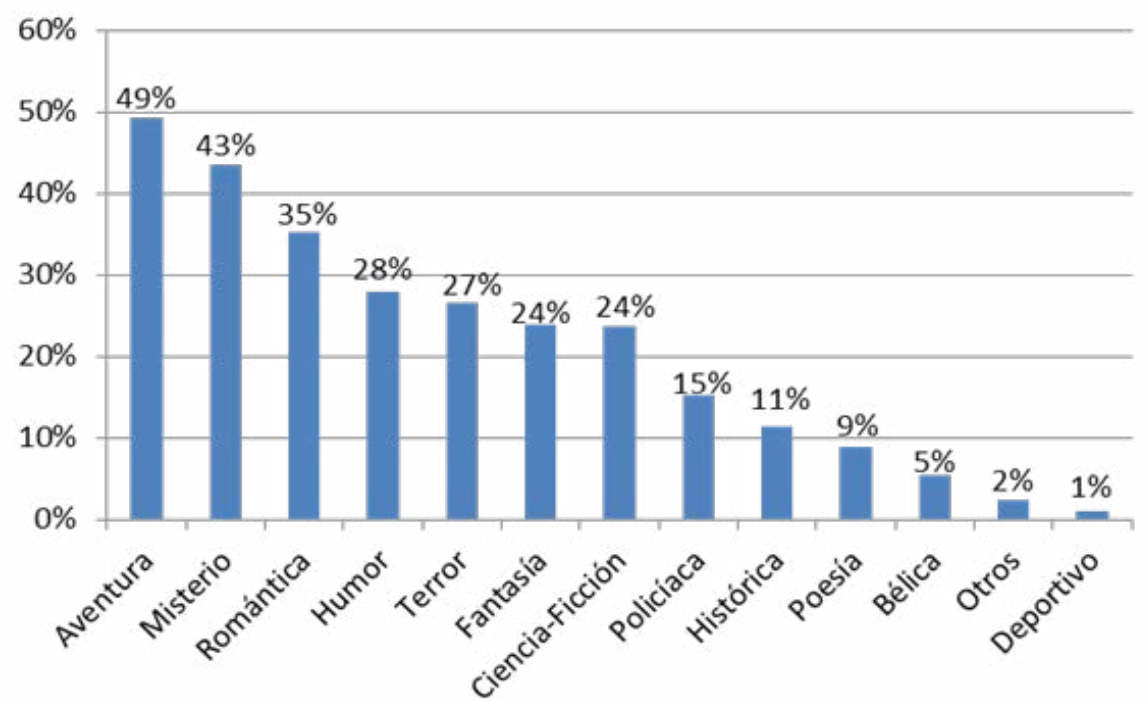

Como observamos en el Gráfico 4, los géneros que menos interesan a los alumnos de Primaria son la novela romántica y la poesía; así, el $43 \%$ de los encuestados afirma que no tiene ningún interés por la novela romántica y $37 \%$ por la poesía. Curiosamente, uno de cada tres alumnos dice no interesarse por los libros de terror y esa misma proporción afirma que son sus lecturas favoritas.

A tenor de lo expuesto en el Gráfico 5, los libros de aventura son los que más agradan en ambos sexos. Ahora bien, mientras que los hombres sienten predilección por los libros de terror, las mujeres la tienen por los de fantasía. Los libros de misterio presentan gran aceptación en los dos sexos. La novela romántica es más apreciada por mujeres que por hombres. La poesía no se sitúa en ningún caso entre los géneros preferidos.

Según el Gráfico 6, en tanto que las mujeres rechazan los libros de terror (bastante aceptados por los hombres), los hombres seleccionan la novela romántica como el género que menos les agrada. La poesía, como hemos advertido antes, presenta un alto porcentaje de rechazo por parte de ambos sexos, especialmente en los hombres. 


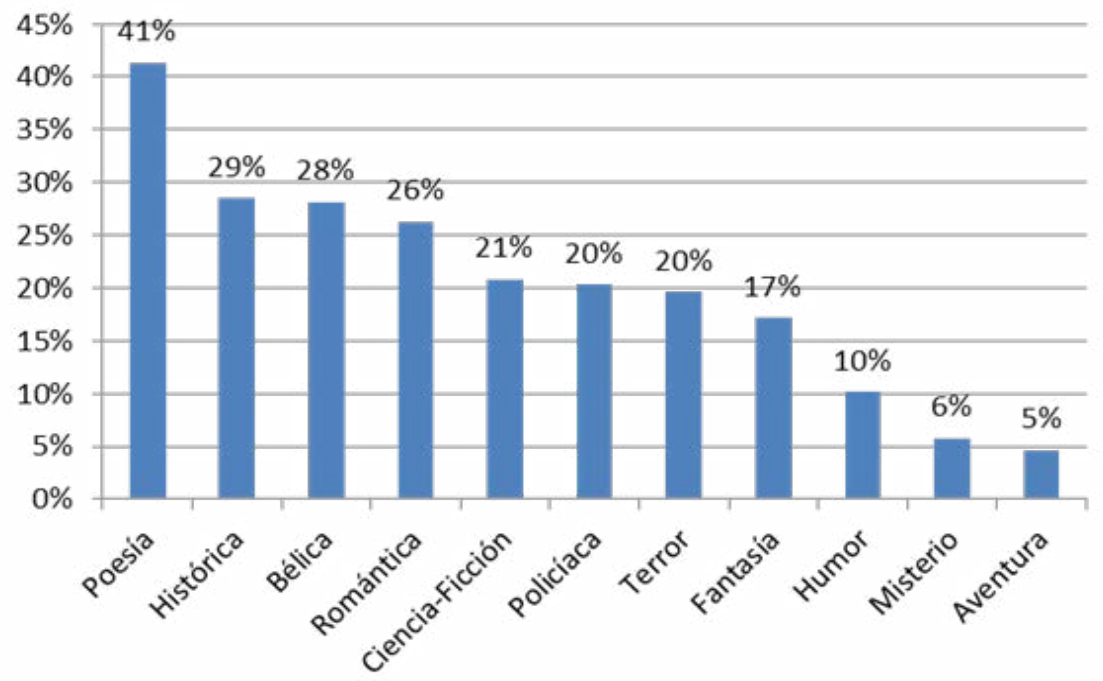

Mujeres
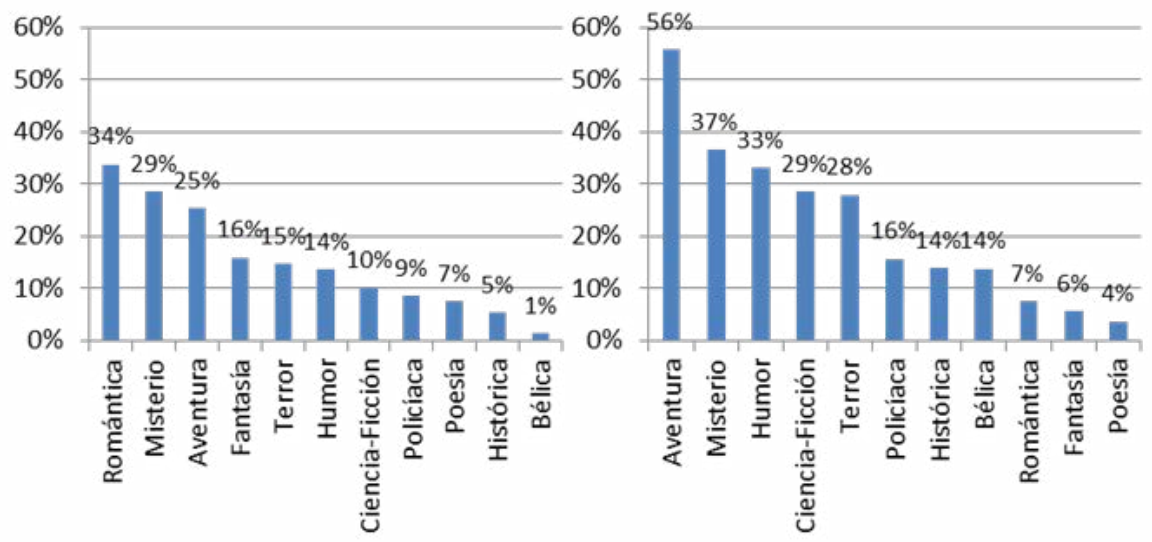

Gráfico 8. Géneros literarios que menos gustan en los alumnos de Secundaria

\subsection{Secundaria}

Como vemos en el Gráfico 7, los libros de aventuras siguen siendo los que más gustan entre los jóvenes, pues casi la mitad de los alumnos ha seleccionado este género como favorito. La poesía, en cambio, resulta uno de los géneros menos seleccionados, a la que se une las novelas bélicas.

Si analizamos el Gráfico 8, a la hora de decidir los géneros que menos gustan, los alumnos de Secundaria señalan de nuevo la poesía en primer lugar, seguida de la novela histórica y la bélica. A pesar de que un $35 \%$ por cierto de los encuestados seleccionaron la novela romántica entre sus favoritas, se da la paradoja de que un $26 \%$ la selecciona también como una de las que menos gustan.

Según el Gráfico 9, mientras que a las mujeres les gusta más la novela romántica, más de la mitad de los hombres se decantan por los libros de aventuras. Los libros de misterio son bastante populares en ambos casos. La ciencia ficción siempre tiene mejor acogida entre los hombres.

El Gráfico 10 demuestra que, aunque la poesía sea el género más rechazado por ambos sexos, el rechazo es mucho mayor entre los hombres que entre las mujeres. El mayor contraste se sitúa en el género de la novela romántica: mientras que un 
Gráfico 10. Géneros literarios que menos gustan en los alumnos de Secundaria según el sexo

Gráfico 11. Géneros literarios favoritos en los universitarios
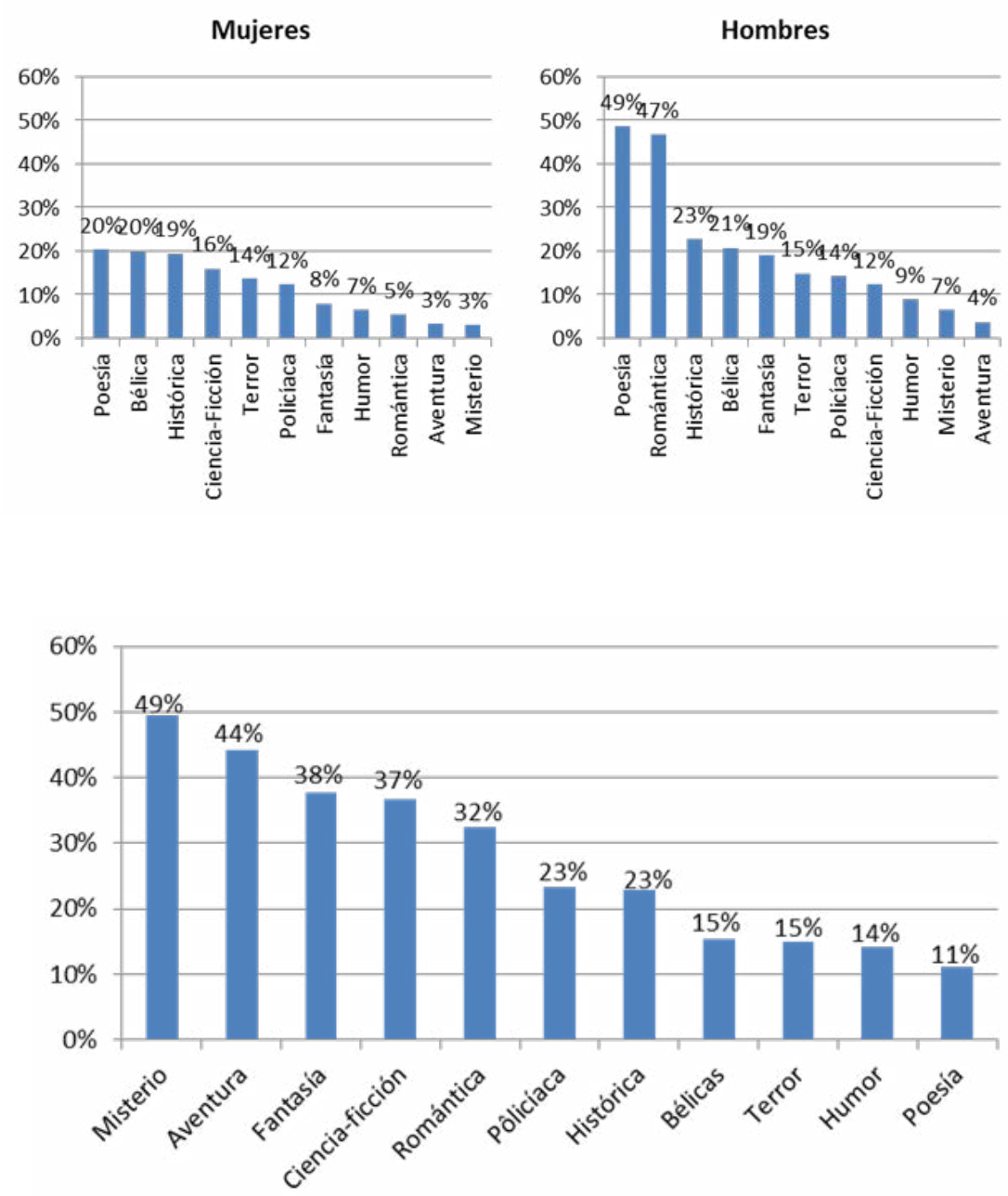

$47 \%$ de los hombres señala que no le gusta ese género, solo un $5 \%$ de las mujeres lo selecciona como el que menos gusta.

\subsection{Universidad}

A través del Gráfico 11, en este nivel educativo la poesía sigue siendo uno de los géneros que menos seleccionan los encuestados, seguida de los libros de humor y de terror. En cambio, a los universitarios les seducen mucho los libros de misterio, que es la opción que elige casi la mitad de ellos. Los libros de aventura cuentan también con una gran aceptación entre quienes leen ficción literaria, ya que obtiene el segundo lugar con un $44 \%$.

Al preguntar directamente por los géneros que menos gustan, la novela romántica y de terror son los seleccionados por estos estudiantes; un $31 \%$ de los encuestados así lo manifiesta. Les siguen la poesía y la novela bélica. Así lo expone el Gráfico número 12.

Si analizamos el Gráfico 13, dentro de los géneros ficcionales, la gran diferencia vuelve a estar en la novela romántica, que es seleccionada mayoritariamente por mujeres, con una diferencia del $45 \%$. Las mujeres también han seleccionado más los libros de misterio, aunque también tiene un porcentaje alto en los hombres. Los varones 


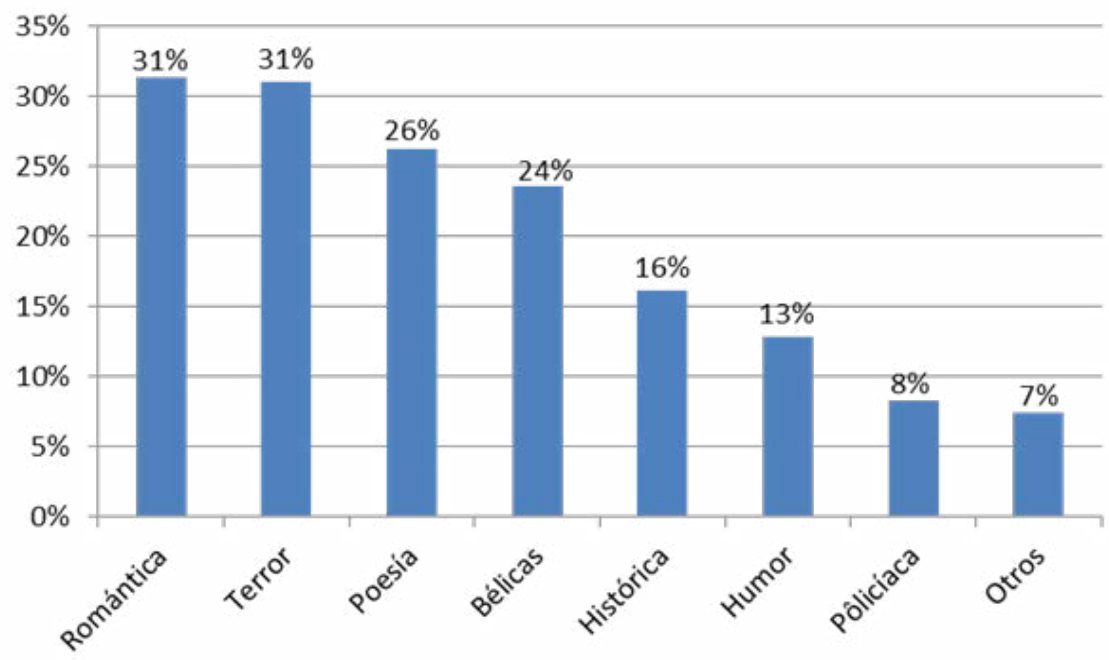

Mujeres

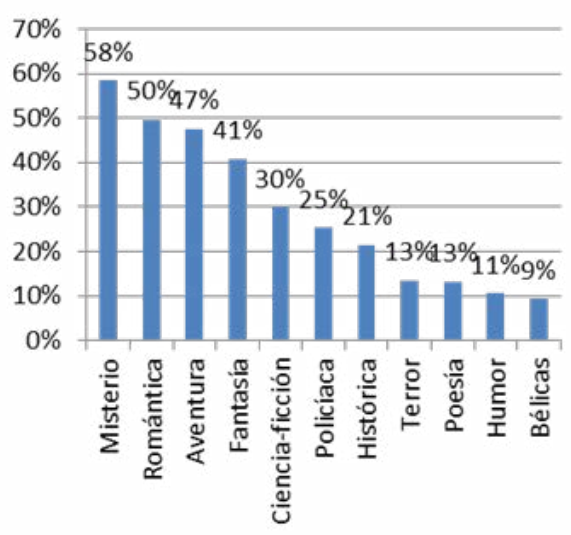

Mujeres

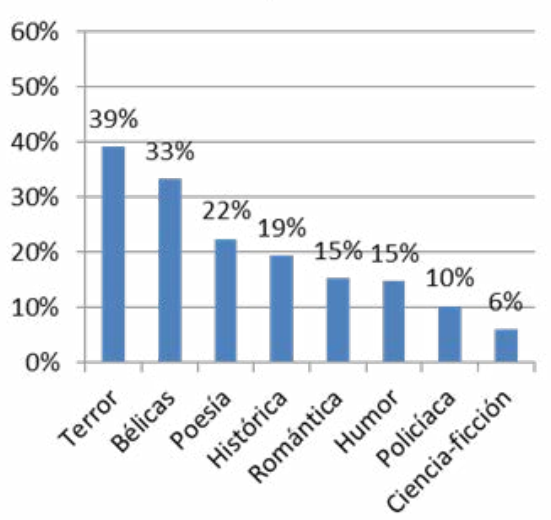

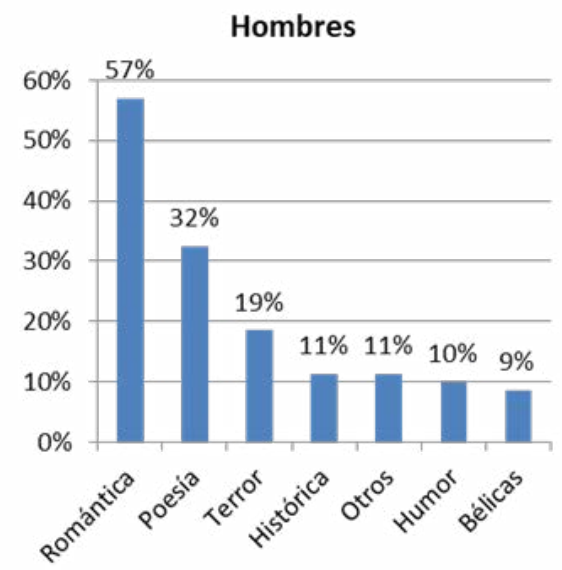

Hombres

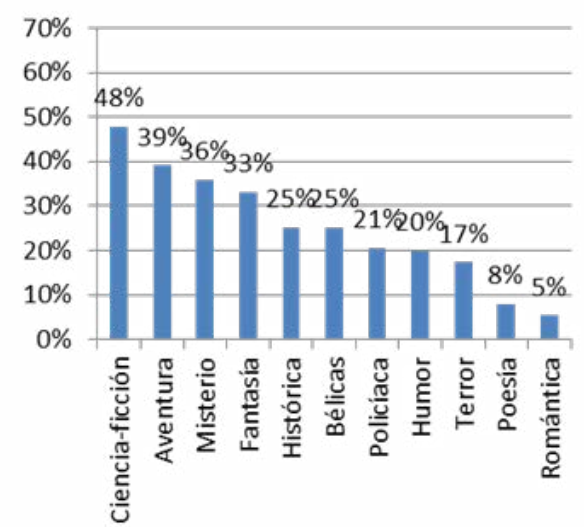

Gráfico 13. Géneros literarios favoritos en los universitarios según el sexo
Gráfico 12. Géneros literarios que menos gustan en los universitarios
Gráfico 14. Géneros literarios que menos gustan en los universitarios según el sexo

seleccionan en primer lugar los libros de ciencia-ficción, con una diferencia del $18 \%$ con respecto a las mujeres.

Según el Gráfico 14, a las mujeres no les seducen los géneros bélico y de terror, mientras que la mayoría de los hombres afirman que a ellos no les gustan los libros 
Gráfico 15. Géneros literarios favoritos en los alumnos de la UMEX

Gráfico 16. Géneros literarios que menos gustan en los alumnos de la UMEX
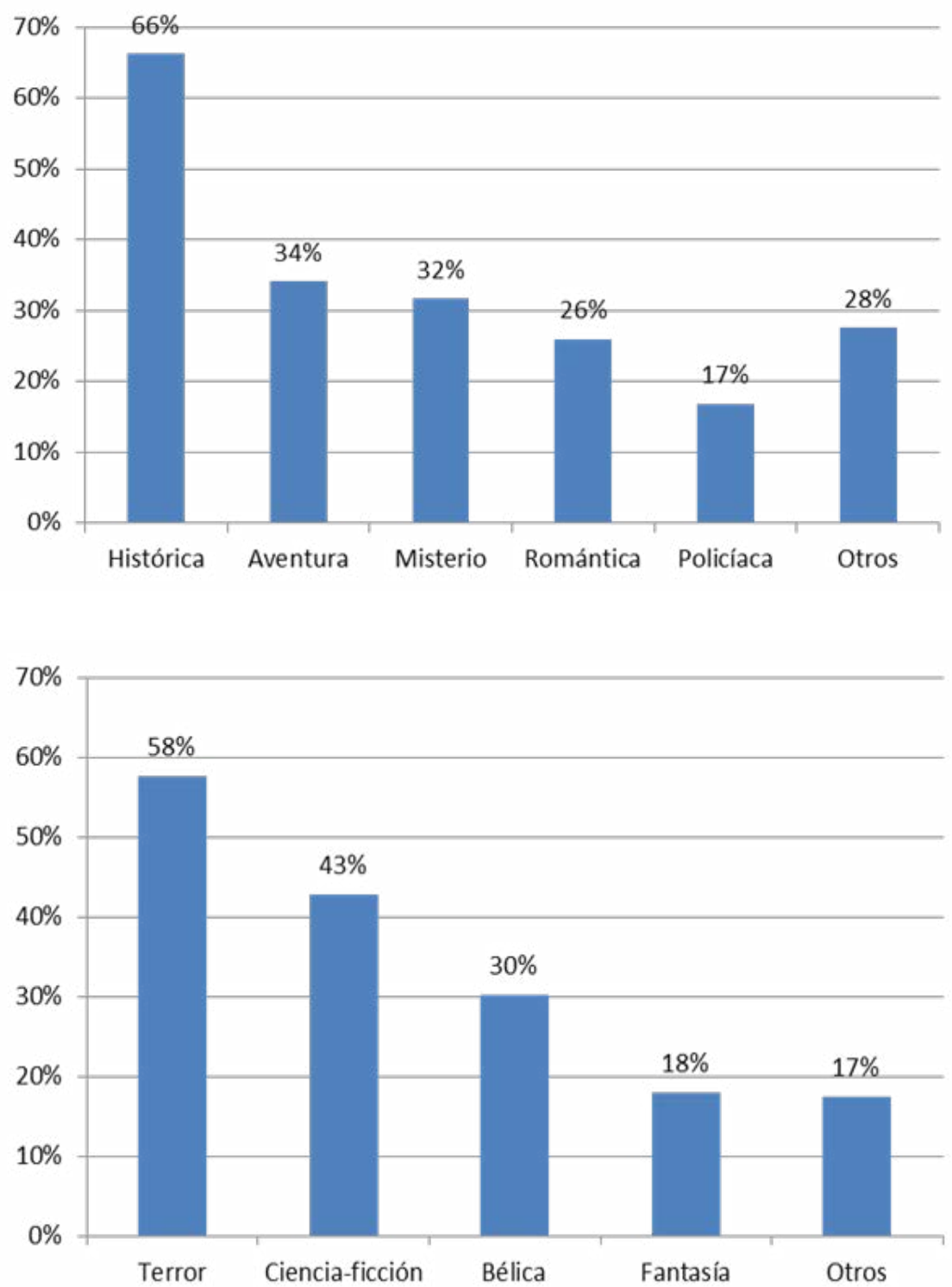

románticos. Como hemos señalado en varias ocasiones, la poesía no es un género muy valorado en ambos sexos.

\subsection{Universidad de Mayores}

Analizando el Gráfico 15, en la Universidad de Mayores cambian considerablemente los gustos lectores con respecto a otros niveles educativos. Entre los mayores de 55 años matriculados en la UMEX el género preferido es la historia, que alcanza un $66 \%$ de los votos. Bastante alejada, con la mitad aproximada de porcentaje, se sitúa la novela de aventuras, seguida por la de misterio y la romántica.

Si observamos el Gráfico 16, los libros de terror son rechazados por más de la mitad de los encuestados, seguidos por la ciencia-ficción. En esta relación de los seis géneros con menos acogida por parte de los encuestados no figura la poesía, que sí estaba en los demás niveles educativos analizados. 
Mujeres

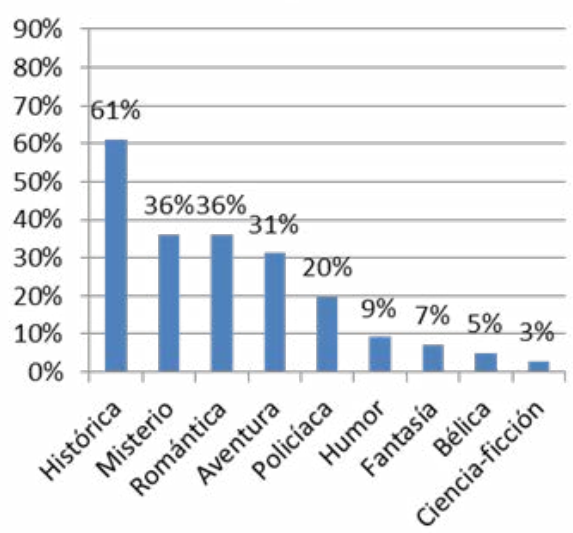

Mujeres

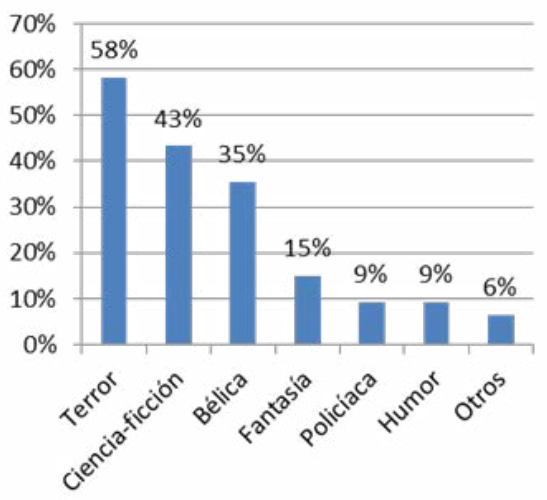

Hombres

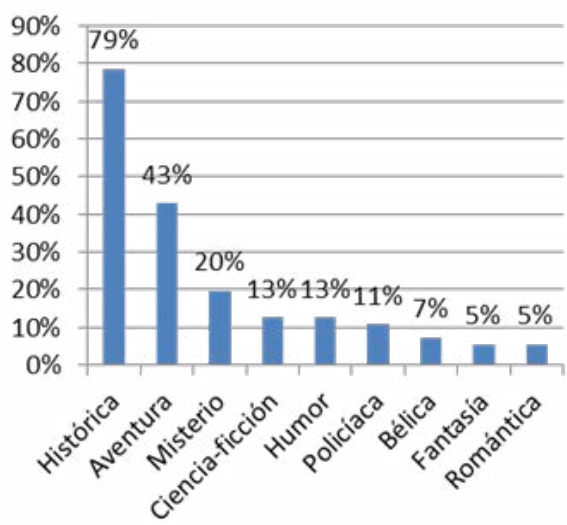

Gráfico 17. Géneros literarios favoritos en los alumnos de la UMEX según el sexo
Gráfico 18. Géneros literarios que menos gustan en los alumnos de la UMEX según el sexo

A tenor de lo expuesto en el Gráfico 17, la novela histórica se consolida como el género favorito entre los alumnos de este nivel, tanto en hombres como en mujeres, si bien entre los hombres presenta mayor aceptación. Los géneros de misterio y romántico son los siguientes tipos preferidos por ellas, mientras que los hombres han seleccionado aventura y misterio como segundo y tercer género predilectos respectivamente. El género de ciencia ficción ha sido seleccionado en cuarto lugar por los hombres, es decir, sigue teniendo una cierta aceptación entre los varones, no así entre las mujeres, que en ningún nivel educativo lo han seleccionado entre sus géneros favoritos. Las lectoras de la UMEX prefieren más los libros de misterio o de corte romántico. Los libros de aventura tienen bastante acogida por parte de ambos sexos, si bien los varones representan en este aspecto un porcentaje mayor.

Según el Gráfico 18, el género de terror es el que menos atrae en ambos sexos, seguido de los libros de ciencia-ficción, aunque ambos porcentajes son mayores en las mujeres. Tras esos dos géneros literarios, a los hombres no les atrae el género romántico mientras que las mujeres no tienen aprecio por la literatura bélica. 
2. http://www.mecd.gob. es/cultura-mecd/

Tabla 4. Préstamos de adultos por CDU

Tabla 5. Préstamos de infantil por CDU

\subsection{Datos relativos a las bibliotecas públicas de Extremadura}

Para reforzar los datos expuestos, mostramos a continuación algunos datos sobre préstamos de libros en las bibliotecas locales y públicas del Estado en Extremadura, en concreto sobre el apartado CDU. Los datos se han obtenido de "Las Bibliotecas Públicas Españolas en cifras", dentro de la web del Ministerio de Educación, Cultura y Deportes (2017), en concreto en la sección de Cultura² ${ }^{2}$.

Particularmente interesantes para analizar los hábitos de lectura en Extremadura resultan los datos referidos a préstamos de adultos por CDU:

\begin{tabular}{|c|c|c|c|c|c|c|c|c|c|}
\hline $\mathbf{0}$ & $\mathbf{1}$ & $\mathbf{2}$ & $\mathbf{3}$ & $\mathbf{5}$ & $\mathbf{6}$ & $\mathbf{7}$ & $\mathbf{8}$ & $\mathbf{9}$ & Total \\
\hline 13.845 & 7.157 & 1.527 & 8.653 & 4.491 & 10.111 & 13.319 & 110.124 & 14.734 & 183.961 \\
\hline
\end{tabular}

Fuente: Ministerio de Educación, Cultura y Deporte

Como podemos observar por la Tabla 4, la CDU 8 (Lenguaje, Lingüística, Literatura) cuenta con el mayor número de volúmenes, lo que refleja la orientación y el gusto de los hábitos lectores especialmente por la ficción literaria. Le sigue el CDU 9 (Geografía, Biografías, Historia), que tradicionalmente ha contado con un buen número de seguidores. En los últimos años se aprecia también un aumento significativo del CDU 6 (Ciencias aplicadas, Medicina, Tecnología), con toda probabilidad debido a la atención por las nuevas tecnologías.

Y muy interesantes también son los datos referidos a préstamos de infantil por CDU:

\begin{tabular}{|c|c|c|c|c|c|c|c|c|c|}
\hline $\mathbf{0}$ & $\mathbf{1}$ & $\mathbf{2}$ & $\mathbf{3}$ & $\mathbf{5}$ & $\mathbf{6}$ & $\mathbf{7}$ & $\mathbf{8}$ & $\mathbf{9}$ & Total \\
\hline 14.750 & 323 & 102 & 1.014 & 1.886 & 1.199 & 1.186 & 36.918 & 897 & 119.730 \\
\hline
\end{tabular}

Fuente: Ministerio de Educación, Cultura y Deporte

Como vemos en la Tabla 5, los préstamos para el público infantil suponen alrededor de un $60 \%$ del total. Como era de suponer, tanto en adultos como en infantil la CDU número 8, referido a Literatura, supone el apartado más destacado con mucha diferencia, si bien los apartados 0,7 y 9 en el apartado de los adultos y o y 5 en el de los niños representan un porcentaje notable. Con todo, como cabía esperar, en el segmento infantil el CDU 8 es aún más destacado que en los mayores. Como hemos dicho, le sigue el CDU 5 (Matemáticas. Ciencias Naturales), con toda probabilidad por la presencia de libros de animales, muy queridos entre el público infantil.

\subsection{Bibliotecas escolares de Extremadura}

La información que sigue en las próximas páginas está contenida en la aplicación (Consejería de Educación de la Junta de Extremadura, 2017) y nos ha sido facilitada por los servicios técnicos de Abies web de las Bibliotecas Escolares de Extremadura gracias a la colaboración de estas instituciones con este grupo de investigación y el Plan de Fomento de la Lectura de la Junta de Extremadura. 249 son los centros que pertenecen a REBEX, Red de Bibliotecas Escolares de Extremadura. 97 pertenecen a la provincia de Cáceres y 150 a la provincia de Badajoz, lo que no se corresponde estadísticamente con la población, pues la provincia de Cáceres tiene 403.665 habitantes en 2016 mientras que Badajoz cuenta con 684.113. En el conjunto de todas las bibliotecas, 151 se sitúan en centros públicos de Educación Primaria, 88 en centros públicos de Educación Secundaria, 2 en centros de Educación Especial, 1 en un centro 

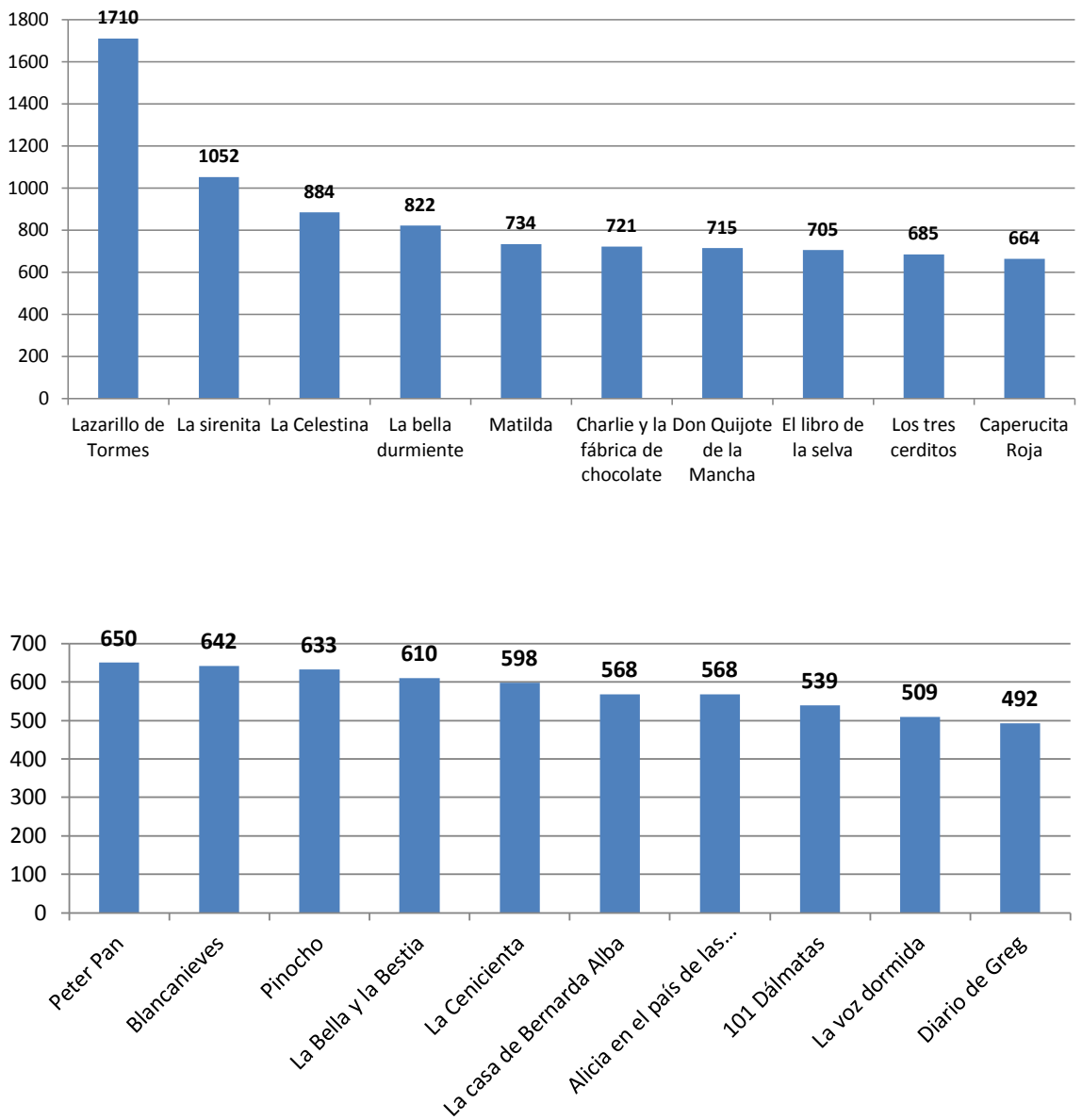

público de Educación de Adultos y 7 en centros concertados. Desde el inicio de la creación de la Red de Bibliotecas Escolares, se han invertido 8.250.000 euros. Desde el curso 2006/07 y hasta el curso 2016/17, periodo en el que aparecen desglosadas las partidas, la inversión económica ha ascendido a 3343295 euros, de los cuales 1.775 .295 euros han correspondido a la Educación Primaria pública, 1.542 .263 a Secundaria pública, 59.000 a centros concertados y 25.743 a otros (Centros de Educación Especial, Centros de Enseñanza para Adultos). Los cursos con más inversión total fueron 2007/2008 y 2012/2013 con incluso más de 600000 euros cada uno; los cursos con menor inversión económica fueron 2013/14 con 70.000 euros y el 2015/16 con solo 7.000 euros. En 2016/2017, último curso del que tenemos datos estadísticos relativos a la inversión, esta se ha recuperado y ha alcanzado los 190500 euros, distribuyéndose de la siguiente forma: 117.015 para Educación Primaria pública, 71.425 para Educación Secundaria pública y 2070 para otros niveles (CEE y CEPA).

En total han sido 508 los centros que han recibido ayudas; hay 1.250 personas trabajando en las bibliotecas escolares; 45.260 alumnos/as que participan en el programa "Leer en familia 2017" y 351 alumnos que participan en el Concurso de Lectura en Público.

Comenzamos con los libros más prestados que ocupan las primeras 20 posiciones. Para ello, si no se indica lo contrario, se establecerá un rango temporal amplio, desde el 2000 hasta la actualidad. Los primeros diez libros más prestados son los los mencionados en el Gráfico 19; las posiciones 11-20 están ocupadas por los libros que muestra el Gráfico 20.
Gráfico 19. Títulos más prestados

Gráfico 20. Títulos más prestados 
Gráfico 21. Préstamos por autores más prestados

Gráfico 22. Préstamos por editoriales más prestados
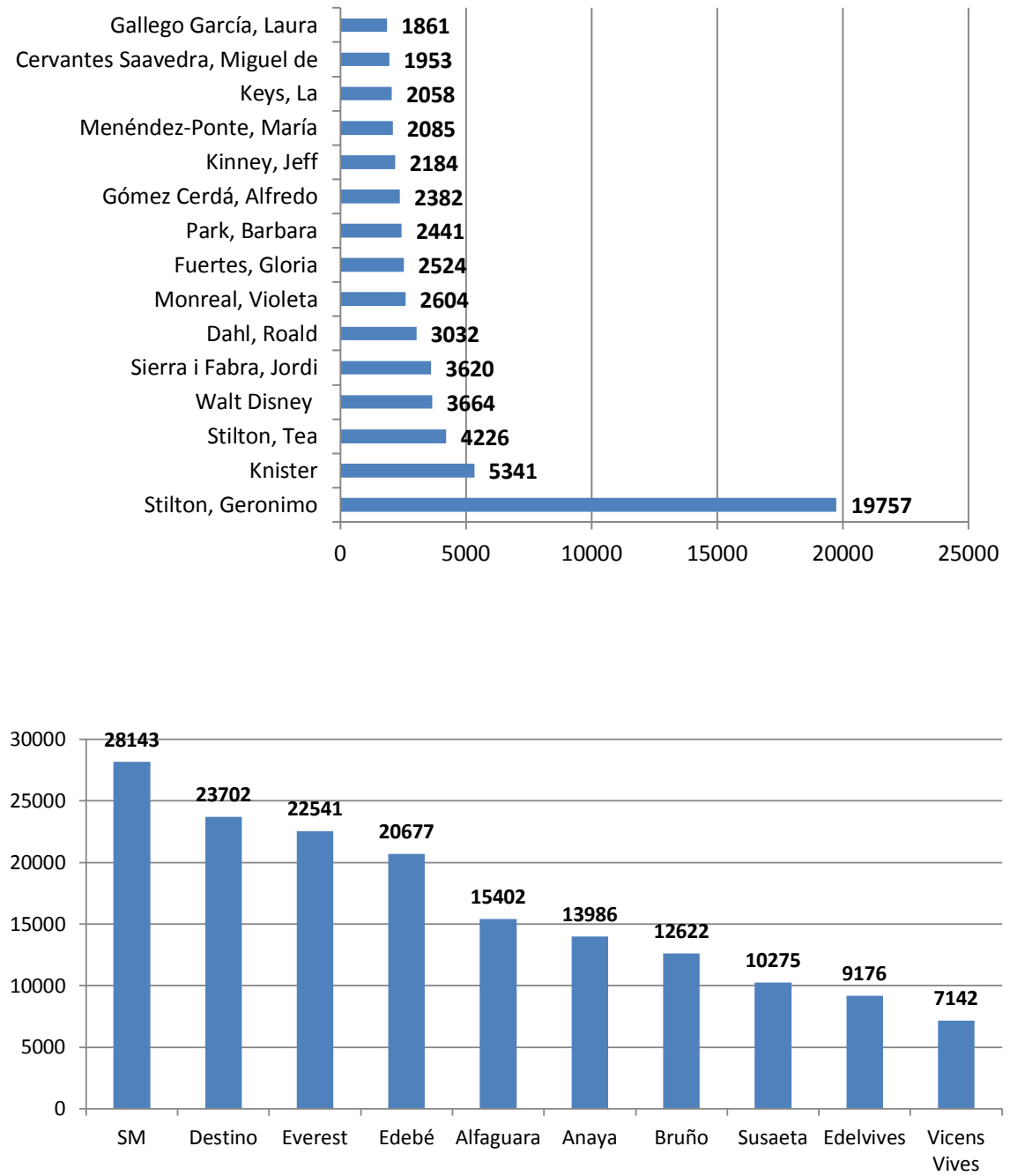

Como vemos en el Gráfico 19, en la relación de los primeros del ránking se alternan clásicos de la Literatura Española (El Lazarillo, La Celestina, Don Quijote de la Mancha) con Literatura Infantil y Juvenil, sean clásicos juveniles o contemporáneos. De los veinte títulos relacionados, solo cuatro pueden considerarse en lengua original española, ya que los otros son traducciones o versiones posteriores de traducciones originales. De cualquier forma, predomina la Literatura Infantil y Juvenil.

En cuanto a los autores más prestados, estos son los primeros: Gráfico 21. En el Gráfico 21 podemos apreciar que los best sellers de Literatura Infantil y Juvenil contemporáneos ocupan los primeros puestos. Por otro lado, el autor español más solicitado es Jordi Serra i Fabra, seguido de Violeta Monreal y Gloria Fuertes. Probablemente en el caso de esta última tiene que ver el hecho de que se ha producido el centenario de su nacimiento.

Las editoriales más prestadas son las que se presentan en el Gráfico 22. Todas ellas son editoriales clásicas de carácter educativo, indexadas con un factor de impacto notable en la plataforma Scholary Publishers Indicators in Humanities and Socials Sciences. 


\section{Conclusiones}

En Educación Primaria el género predilecto es el de aventuras (62\%), mientras que el segundo lugar lo ocupa la novela de misterio (40\%). Idénticos resultados obtenemos en Secundaria, aunque los porcentajes difieren ligeramente: $49 \%$ para aventura y $43 \%$ para misterio.

Si bien los dos géneros comentados siguen siendo muy importantes para los estudiantes universitarios, se producen ligeras variaciones en cuanto a su orden y sus porcentajes. Así, el género más atractivo es el de misterio (49\%), seguido del relato de aventuras (44\%). Por último, los estudiantes del Programa de la Universidad de Mayores muestran un mayor interés por la novela histórica (66\%) seguido del género de aventuras (34\%). Los géneros de aventura y misterio son, pues, los más apreciados en todos los niveles.

Se dan importantes diferencias de porcentajes en algunos niveles y géneros. La mayor diferencia en Primaria es la del $45 \%$ del género fantástico en mujeres por un $23 \%$ en los hombres. Mientras que en Secundaria este mismo género se da en el $16 \%$ en las mujeres y en el $6 \%$ en los hombres.

Los libros de poesía, de temática romántica y de terror son los menos apreciados por los encuestados de Educación Primaria y Universidad. En la Educación Secundaria se mantendría la poesía, acompañada de la novela histórica y la novela bélica.

La novela romántica es la que menos gusta a los lectores de Educación Primaria (43\%), seguida de la literatura lírica (37\%). Por otro lado, en educación Secundaria se produce un ligero cambio, siendo en esta ocasión la poesía el género que menos pasiones levanta (41\%), bastante distanciado del segundo, la novela histórica $(28 \%)$.

Los géneros de novela romántica y de terror son los que menos gustan en la Universidad, con un porcentaje similar ( $31 \%$ ). En la Universidad de Mayores destaca uno por encima del resto, el texto de terror con un $58 \%$, seguido por el de ciencia-ficción (43\%), es decir, el $43 \%$ de los lectores dicen que el género que menos gusta es la novela romántica.

El género con mayor diferencia por sexos es el de la novela romántica, que en Primaria es del $33 \%$ en mujeres por un $54 \%$ en los hombres. En Secundaria este mismo género se da en el $5 \%$ en mujeres y $47 \%$ en hombres.

En cuanto a la información obtenida desde las bibliotecas públicas, el CDU número 8 , relacionado con la Literatura, resulta aún el más prestado y leído, y los fondos y las compras así lo atestiguan. Le siguen el CDU 5 (Naturaleza) en préstamos infantiles, y el CDU 9 (Historia) en préstamos para adultos. Llama la atención también el notable préstamos (suponemos que cada vez mayor) de libros relacionados con las nuevas tecnologías. Existe una relación directa entre las fuentes consultadas, especialmente en lo relativo a la frecuencia del CDU.

En cuanto a las bibliotecas escolares, dentro de la Literatura (CDU 8), los más prestados siguen siendo los clásicos de la Literatura Española (en bibliotecas escolares, por su dimensión de lecturas obligatorias) junto a los best sellers recientes de literatura infantil y juvenil, sea extranjera o nacional.

En suma, muy telegráficamente, los géneros literarios de misterio y aventuras son, en general, los más demandados en todos los niveles educativos. En la Universidad de Mayores se prefieren los de historia. La novela romántica gusta más a las mujeres que a los hombres. El género lírico no atraviesa un buen momento en cuanto a las preferencias de lectura en ninguno de los niveles educativos analizados. 


\section{Referencias bibliográficas}

"Bleotu, Vasile y Tilea Doina Maria. 2014. Strategic Priorities for Education Funding. En Procedia. Social and Behavioral Sciences. Vol. 116, 2231-2234. https://doi. org/10.1016/j.sbspro.2014.01.549.

»Colomer Martínez, Teresa. 1993. La enseñanza de la lectura. Estado de la cuestión. En Cuadernos de Pedagogía. Vol. 216, 15-18.

"Comunidad de Madrid 2010. Hábitos de lectura y compra de libros en la Comunidad de Madrid. <http://www.madrid.org/cs/Satellite?blobcol=urldata\&b lobheader=application $/$ pdf\&blobheadername1=Content - Disposition\&blobh eadervalue1=filename\% $3 \mathrm{DH} \% \mathrm{C}_{3} \% \mathrm{~A}_{1}$ bitos +de+lectura+2010+CM.pdf\&blob $k e y=i d \& b l o b t a b l e=$ MungoBlobs\&blobwhere $=1271881547480 \&$ ssbinary $=$ true $>$ [Consulta: 20 septiembre 2017].

»Consejería de Educación de la Junta de Extremadura 2017. Datos sobre bibliotecas escolares de Extremadura. <http://abiesweb.educarex.es/index.php/signin> [Consulta: 30 septiembre 2017].

» Fundación Germán Sánchez Ruipérez. 2007. Hábitos de lectura y compra de libros en Extremadura 14 a 24 años. Mérida: Plan de Fomento de la Lectura en Extremadura.

» Fundación Germán Sánchez Ruipérez. 2009. Estudio de hábitos de lectura y compra de libros en la Comunidad de Castilla y León. Junta de Castilla y León.

»Generalitat de Catalunya 2016. Hàbits de lectura i compra de llibres a Catalunya. 2015. <https://issuu.com/icec_generalitat/docs/h_bits_de_lectura_a_catalunya_2015/46> [Consulta: 20 de septiembre de 2017].

"Gil Flores, Javier. 2009. Hábitos y actitudes de las familias hacia la lectura y competencias básicas del alumnado. En Revista de Educación. Vol. 350, 301-322.

»Goksu, Alper y Gonka Gungor. 2015. A Comparative Analysis of Higher Education Financing in Different Countries. En Procedia. Economics and Finance. Vol. 26, 1152-1158. https://doi.org/10.1016/S2212-5671(15)00945-4

"Grecu, Mihaela; Emilia Titan y Elena Druica. 2015. Investigating the Costs of Education in the European Union. En Procedia. Economics and Finance. Vol. 23, 8o8-817. https://doi.org/10.1016/S2212-5671(15)00592-4

» Gremio de libreros de Madrid 2016. Mapa de Librerías Observatorio de la Librería en España: Año 2015. Madrid: Observatorio de la Librería de CEGAL- MECD.

» latagan, Mariana 2015. Challenges of the Romanian higher education system in the context of globalization. En Procedia. Social and Behavioral Sciences, Vol. 180, 345-351. https://doi.org/10.1016/j.sbspro.2015.02.127

» Junta de Extremadura. 2017. Atlas socioeconómico de Extremadura. <http://estadistica.gobex.es/web/guest/atlas-socieconomico-de-extremadura> [Consulta: 11 noviembre 2017].

» López-Rodríguez, Jesús y José Andrés Faíña 2014. Rhomolo and other methodologies to assess The European Cohesion Policy. En Investigaciones regionales. Vol. 29, 5-13.

" Mate-Sanchez-Val, Mari Luz y Richard Harris. 2014. Differential empirical innovation factors for Spain and the UK. En Research Policy. Vol. 43, 451-463. 
» Millán, José Antonio. coord. 2017. La lectura en España. Informe 2017. Madrid: Federación de Gremios de Editores de España.

» Ministerio de Educación, Cultura y Deporte 2013-2014. Nube de lágrimas. Club de lecturas en la nube; E-book +18-40. Los lectores y los libros electrónicos; y Hábitos de lectura y compra de libros en España 2012. <http://www.mecd.gob.es/cultura-mecd/ areas-cultura/libro/mc/observatoriolect/redirige/estudios-e-informes/elaboradospor-otras-entidades-con-la-colaboracion-del-ministerio/lectura.html> [Consulta: 13 enero 2018].

» Ministerio de Educación, Cultura y Deporte 2014: La participación de las familias en la educación escolar. <http://www.mecd.gob.es/dctm/cee/publicaciones/estudioparticipacion/estudioparticipacion.pdf?documentld=0901e72b81b45e3> [Consulta: 3 marzo 2018].

» Ministerio de Educación, Cultura y Deporte 2016. PISA 2015: Informe Español. Madrid: INEE.

" Ministerio de Educación, Cultura y Deporte 2016: El sector del libro en España 20132015. <http://www.mecd.gob.es/dms/mecd/cultura-mecd/areas-cultura/libro/mc/ observatoriolect/redirige/estudios-e-informes/elaborados-por-el-observatoriolect/sector-libro-abril2015/sector-libro-abril2015.pdfs [Consulta: 3 marzo 2018].

» Ministerio de Educación, Cultura y Deporte 2017. Bibliotecas públicas españolas en cifras. <http://www.mecd.gob.es/cultura-mecd/areas-cultura/bibliotecas/mc/ ebp/portada.html> [Consulta: 11 marzo 2018].

" Moret, Zulema. 1999. Animar a escribir para animar a leer. Salamanca: Fundación Germán Sánchez Ruipérez.

» Muñoz Rodríguez, José Manuel y Azucena Hernández Martín. 2011. Hábitos lectores de los alumnos de la ESO en la provincia de Salamanca. ¿Son el género y el entorno factores diferenciales? En Revista de Educación. Vol. 354, 605-628.

»Nieto Masot, Ana y José Luis Gurría Gascón. 2005. Análisis de la población de los programas de desarrollo rural en Extremadura mediante sistemas de información geográfica. En BIBLID. Vol. 36, 479-495.

"Nieto Masot, Ana y Gema Cárdenas Alonso. 2015. El Método LEADER como política de desarrollo rural en Extremadura en los últimos 20 años 1991-2013. En Boletín de las Asociación de Geógrafos Españoles. Vol. 69, 139-162.

»Observatorio de la lectura y el libro. 2015. Panorámica de la edición española de libros 2015. Análisis sectorial del libro. Madrid: MECD.

»Observatorio de la lectura y el libro. 2016. El libro digital. Aproximación a la realidad de las editoriales presentes en LIBER 2015. Madrid: MECD.

»Observatorio de la lectura y el libro. 2017. El sector del libro en España. Madrid: MECD.

》 Olaziregi Alustiza, María José. 200o. Aproximación sociológica a los hábitos de lectura de la juventud vasca. En BIBLID. Vol. 18, 79-93.

"Poulain, Martine. ed. 1988. Pour une sociologie de la lectura. Paris: Editions du Cercle de la Librairie.

»Ramajo Hernández, Julián; Miguel Ángel Márquez Paniagua y Francisco Javier Miguel Vélez. 2014. Economic impact of the European Funds in Extremadura during the period 2007-2013. En Investigaciones regionales. Vol. 29, 113-128.

» Serna, Maite; Arantzazu Rodríguez y Xavier Etxaniz. 2017. Biblioteca escolar y hábitos lectores en Educación Primaria. En Ocnos, Vol. 16, no. 1, 18-49. 
